\title{
A Continuous, High-Frequency Environmental Monitoring System for Watershed Education Research
}

\author{
Walter M. McDonald \\ Department of Civil \& Environmental Engineering, \\ Virginia Tech, Blacksburg, VA 24060, USA. \\ e-mail: walmcdon@vt.edu, 817-703-4698 \\ Randel L. Dymond \\ Department of Civil \& Environmental Engineering, \\ Virginia Tech, Blacksburg, VA, 24060, USA \\ e-mail: dymond@vt.edu
}

\author{
Vinod K. Lohani \\ Department of Engineering Education, \\ Virginia Tech, Blacksburg, VA, 24060, USA. \\ e-mail: vlohani@vt.edu \\ Daniel S. Brogan \\ Department of Engineering Education, \\ Virginia Tech, Blacksburg, VA, 24060, USA. \\ e-mails: danielsbrogan@gmail.com
}

\begin{abstract}
The Learning Enhanced Watershed Assessment System (LEWAS) is an environmental monitoring lab on the Virginia Tech, USA campus that uses contemporary sensing and computing technologies to provide high-frequency (1-3 minute sampling intervals) continuous water and weather data from a small urban watershed $(2.78 \mathrm{~km} 2)$ in order to promote watershed research and education. The LEWAS integrates custom software applications with data collection hardware, environmental sensors, and renewable power to create a remote automated watershed monitoring system. Watershed education research is illustrated through case studies based on LEWAS data that demonstrate the value of continuous flow and water quality data in small urbanized watersheds through the capture and characterization of acute hydrologic and hydro chemical events. Student-centered active learning modules that incorporate LEWAS data and case studies have been successfully implemented into an undergraduate hydrology course at Virginia Tech. Assessment results reveal positive student perceived learning gains from instructional activities that incorporate LEWAS data.
\end{abstract}

Keywords: engineering education, active learning, high frequency environmental monitoring, hydrology

\footnotetext{
Walter M. McDonald

Department of Civil \& Environmental Engineering,

Virginia Tech, Blacksburg, VA 24060, USA.

e-mail: walmcdon@vt.edu, 817-703-4698
}

\section{Introduction}

Recent advances in sensor technologies have enabled scientists and engineers to remotely capture environmental data at higher frequencies and over larger spatial scales than was previously possible. These technological applications include remote realtime water monitoring systems that provide automated and continuous data collection. An example of real-time watershed monitoring on a large scale is provided by the United States Geological Survey (USGS). The sensor network of this federal agency records flow and, at some locations, water quality parameters in real-time (no shorter than 15 minute intervals) for nearly 15,000 continuous monitoring stations across the United States (U.S Geological Survey, Real-Time Water Data for the Nation.AccessedMarch,2015.http://waterdata.usgs.g ov/nwis/rt).Remote water monitoring applications have numerous advantages over traditional field sampling techniques including reduced field site visits, continuous data collection, real-time transmission of data and automated data processing. In addition to these benefits, remote data collection with contemporary sensors can be employed at highfrequencies to better capture hydrologic responses of the watershed, thus allowing a complete characterization of the hydrologic and hydrochemical processes.

Most watershed water quantity and quality studies are based on hourly or daily measurements. However, there is growing interest in monitoring water data at 
higher frequencies to better capture hydrologic responses in a watershed (Kirchner et al., 2004). Realtimecontinuous data collection has recently been used in many applications to study water quantity concerns and is also becoming increasingly important for evaluating water quality .There have been many watershed studies that employ environmental sensors to collect flow and water quality data at sampling intervals of less than 30 minutes (Arnscheidt et al., 2005; Jones et al., 2011; Kavetski et al., 2011; Aubert et al., 2014) and even down to 5 minutes (Moraetis et al., 2010). These studies have demonstrated the need to deploy sensors atfrequent sampling intervals in order to detect certain hydrologic and hydro-chemical behaviors in watershed and riverine systems.

In addition to usingreal-time continuous data in watershed research, there is a growing use of such data in educational applications. In New York, water quality sensors have been employed to teach Science, Technology, Engineering, and Mathematics (STEM) principles to over 1,700 middle school and high school students across the state .At the University of Northern Iowa, educators are developing an outdoor data acquisition and transmission site to teach hydrology concepts in the classroom.Applications such as these are recognized as important in creating student-centered learning environments in hydrology education (Thompsonet al., 2012).

The Learning Enhanced Watershed Assessment System (LEWAS)(http://lewas.centers.vt.edu) is an environmental monitoring lab on the Virginia Tech (VT) campus in the United States. This system captures continuous real-time water and weather data for the purposes of watershed education research and educational outreach. The lab was created as part of an engineering education research project(Delgoshaei, 2012; Delgoshaei and Lohani, 2014) supported by the National Science Foundation at VT. One key strength of this interdisciplinary lab is the diversity of students' academic backgrounds (civil \& environmental engineering, engineering education, electrical and computer engineering, computer science, chemical engineering and biology). The LEWAS has various components including water and weather monitoring instruments, renewable power supply, data collection hardware, and custom data processing software which are uniquely integrated to provide real-time watershed monitoring data through a live data viewing website (http://www.lewas.centers.vt.edu/dataviewer/).An important research aspect of the LEWAS is the collection of data at high frequencies (1-3 minutes) within a small urban watershed. This allows the LEWAS lab to capture the hydrologic responses of the watershed as well as unpredicted ephemeral watershed events that may go unnoticed at less frequent sampling intervals. The LEWAS lab has also been integrated into multiple courses across the Engineering Education, Civil and Environmental Engineering, and Geosciences Departments at VT. Classroom objectives in each of these courses are supported by LEWAS-based course modules that actively engage students in data collection, data processing, hydrology, and watershed sustainabilit y concepts through a combination of virtual data collection and field site visits.

This paper describes the LEWAS lab and demonstrates the utility of continuous environmental data in watershed education research and undergraduate hydrology education. The methodology focuses on how water monitoring sensors are integrated together through custom data collection hardware and software to create an efficient and reliable data collection and processing system. It also covers the educational theories and methods that were used to assess how student perceived learning was impacted by use of the LEWAS. Case studies developed using the LEWAS data illustrate the utility of a real-time continuous watershed monitoring lab for watershed research. Finally, examples of active, student-centered learning modules that incorporate LEWAS data and case studies into an undergraduate hydrology course at VT are described and assessment results of student learning are presented.

\section{Site Description}

The LEWAS field site is located within the Stroubles Creek watershed at the outlet of the Webb Branch sub-watershed, just upstream of a series of retention ponds known as the Duck Pond on the VT campus. The watershed (Figure 1b) has an area of 2.78 $\mathrm{km} 2$ and is highly urbanized with residential and commercial development, encompassing portions of the Town of Blacksburg and the VT campus. The Stroubles Creek watershed (Figure 1a), located in Montgomery County, Virginia, is a mixed land use watershed with the headwaters in the Town of Blacksburg, followed by agricultural fields and forested are asnearits outlet. The watershed begins its drainage along the eastern continental divide of the U.S., with water eventually draining to the New, Kanawha, Ohio, and Mississippi Rivers. Stroubles Creek was chosen as the site of the lab because of its 
location on the VT Campus and its environmental significance, as it was 303 (d) listed as impaired by the Virginia Department of Environmental Quality (VDEQ)beginning in 1996 to the most recent report in 2012 . Some of the stressors of the stream include sedimentation, urban pollutants, increased development, and stream channel modifications.
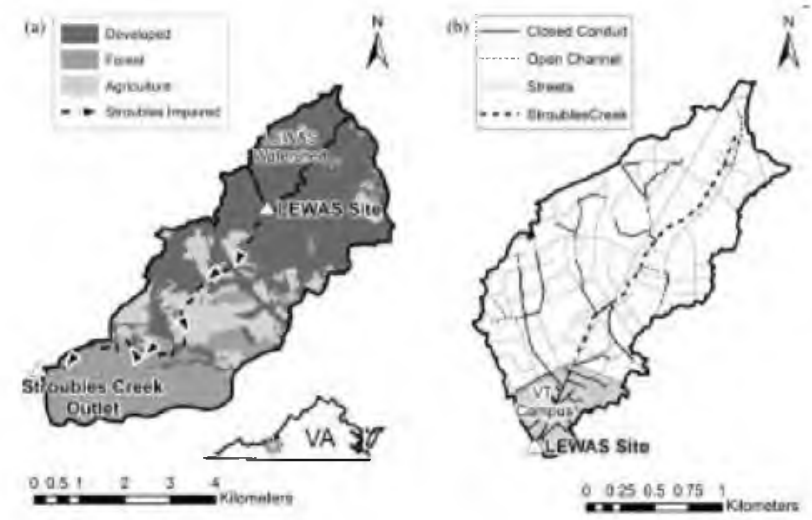

Figure.1 (a) Land Use Map of the Stroubles Creek Watershed, and (b) Stormwater Network Map of the LEWAS Watershed.

\section{Methodology}

The goal of the LEWAS is to provide continuous, reliable, accurate, and real-time dataflow from the sensors at the site to remote end users for research and education. The four primary components of the LEWAS which work together to meet this goal are: (1) water and weather monitoring instruments, (2) power supply, (3) data collection hardware, and (4) data processing software. All four components are integrated together by an interdisciplinary team to enable the LEWAS to measure, collect, transmit, and publish continuous real-time environmental data. Continued development of the system is part of an ongoing Engineering Education $\mathrm{PhD}$ dissertation.

\subsection{Interdisciplinary Team}

To develop and maintain a continuous real-time environmental system requires skills and expertise from a variety of disciplines. The LEWAS lab is comprised of an interdisciplinary team of researchers representing backgrounds in civil and environmental engineering, electrical engineering, computer engineering, computer science, chemical engineering, biology, and engineering education. Currently, the LEWAS team has 3 Engineering Education $\mathrm{PhD}$
Students of which 1 has a Computer Engineering degree, 1 has a Computer Science degree and 1 has an Electrical Engineering degree, 1 Civil and Environmental Engineering PhD student, 2 Civil and Environmental Engineering Masters students, 1 Civil and Environmental Engineering undergraduate student, and 1 Computer Science undergraduate student. All team members bring their own set of skills to ensure that the system delivers reliable and accurate data in real-time from the sensors. For example, power supply and data acquisition require the expertise of personnel from electrical and computer engineering backgrounds while water quality, flow, and weather studies require personnel with civil and environmental engineering backgrounds. In addition, team members work together to develop and implement educational modules for courses in multiple departments at VT and Virginia Western Community College (VWCC). For example, in the spring 2015 semester alone, the LEWAS was used in 4 courses at VT and 2 at VWCC, reaching over 1,800 students. Existing efforts are also building collaborations between the LEWAS team and investigators at other institutions in the U.S., India and Australia to use LEWAS data as well as replicate the LEWAS-type lab at their respective locations.

\subsection{Environmental Sensors}

The LEWAS lab has five primary environmental monitoring sensors that monitor flow, water quality, and weather parameters at the outdoor site (Table 1). The first is a Sontek Argonaut-SW Acoustic Doppler Current Profiler (ADCP) that measures velocities in a natural stream cross section. The second is a Global Water WL705 ultrasonic level transducer that collects stage measurements behind a weir for a secondary flow measurement. The third is a Hydrolab MS-5 Sonde that measures water quality parameters from within the stream channel. The fourth, a Vaisala Weather Transmitter WXT520 measures air temperature, barometric pressure, relative humidity, precipitation and wind. Finally, a tipping bucket rain gage provides additional precipitation measurements at the site. These instruments are connected through underground conduits to a main control box that houses the batteries, solar regulator, and data collection hardware. The ADCP and water quality Sonde are installed in a natural run of the stream, the ultrasonic level transducer is installed in an upstream culvert behind a trapezoidal weir, and the weather transmitter, solar panels, network camera, and directional antenna are installed on a light pole near 
the site. A physical layout of the LEWAS lab equipment is illustrated in Figure 2.

Table 2. LEWAS Sensors

\begin{tabular}{|c|c|c|c|}
\hline Name & Tye & Parmeters & Sempling Interve \\
\hline SoatekAponadt-SW & $\begin{array}{l}\text { Acoustic Doppler } \\
\text { Cinent Profiler } \\
(\mathrm{ADCP})\end{array}$ & vielocity and stage for low estimater & 1 minte \\
\hline Global Weder WL7IIS & $\begin{array}{l}\text { Ultrasonic level } \\
\text { transcoucer }\end{array}$ & stage betilinda weir & 1 minute \\
\hline Hydolab MSS-5 & $\begin{array}{l}\text { Multi-parander } \\
\text { weiler quality Sonde }\end{array}$ & 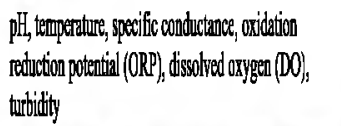 & 3 mintes \\
\hline Vaisale WXT520 & Neather tranminitter & 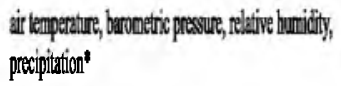 & $\begin{array}{l}\text { Sminutes, } \\
\text { Finstantaneouldy }\end{array}$ \\
\hline $\begin{array}{l}\text { Weathetronotics Iipping } \\
\text { Bucket }\end{array}$ & Rain Gage & prexipitation & instantareacusly \\
\hline
\end{tabular}

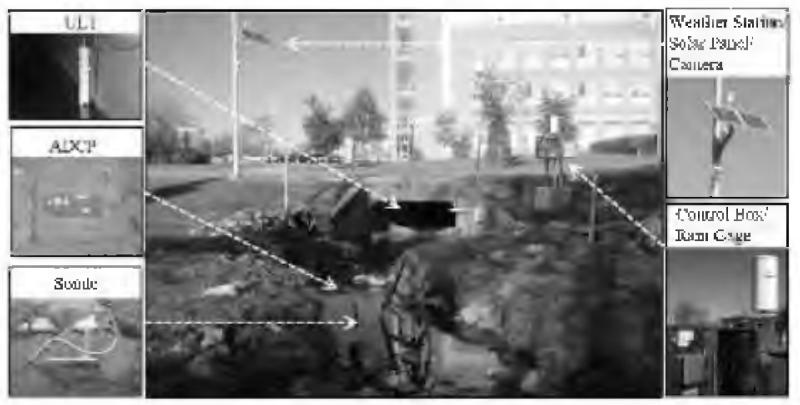

Figure2. LEWAS Lab Physical Layout.

\subsection{Data Acquisition Hardware}

The data collection hardware is composed primarily of a Raspberry $P i$ that continuously runs the remote system. A Rasperry Pi is a credit card sized, low cost computer that can be used for a variety of purposes (Upton and Halfacree, 2014). At the LEWAS site, the Raspberry Pi runs custom Python programs developed by the LEWAS' computer science/engineering team, to collect, analyze, and transmit data from each environmental sensor. The output from the three sensors are sent via RS-232 serial links to the Raspberry Pi, and stored in a local database on the device. A wireless bridge and 14dB directional antenna enable the Raspberry $\mathrm{Pi}$ to establish a wireless connection to the campus wireless network though a point-to-point connection from the LEWAS field site to an access point installed on a nearby campus building. Data is periodically sent from the local database on the Raspberry Pi to a secure database on VT campus where the data is accessed and displayed through the live data viewing website (http://www.lewas.centers.vt.edu/dataviewer/). An
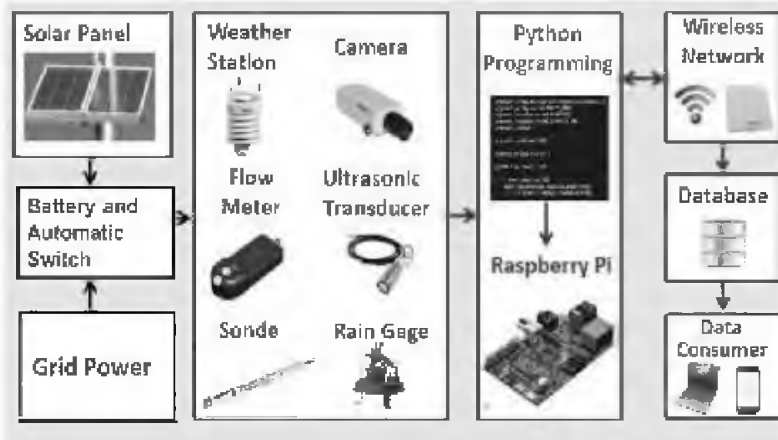

Figure 3. LEWAS Operational Diagram.

operational diagram illustrating the connectivity of the lab is given in Figure 3.

The system is primarily powered by renewable energy through the use of battery backed solar panels mounted on a light pole near the site, but is backed up by a connection to grid power. These solar panels have a peak power generation of 80 Watts and charge two 12 Volt, 30 Amp Hour deep cycle batteries connected in series that are located in the control box and in turn, power the instruments and data transmission 24 hours a day. The batteries have enough storage capacity to sustain the outdoor lab during most evenings and extended overcast periods. However, the system is backed up by a connection to grid power in case the battery capacity gets overwhelmed by demand from the sensors.

\subsection{Programming and Software}

A unique component of the LEWAS is the common programming interface that is used to communicate with, and collect data from, three different proprietary environmental sensors. Each sensor comes with its own data collection software and data loggers that are recommended by the manufacturers to deploy and collect data from the sensors. However, purchasing separate software and data loggers is expensive and limits the ability to deploy, collect, and transmit data from a common interface. To create a common interface, the data collection commands from each proprietary sensor's software were reconstructed using custom Python programs. In each case, the main objective was to determine how an individual sensor sends and receives information through its proprietary software and then code that information into a custom program. The data logging system for LEWAS is a 
unified interface that interacts with multiple environmental monitoring sensors from different manufacturers all through a common data logger (Raspberry Pi) programmed with custom Python software. This method of data collection removes the need for expensive software and data collection hardware for each device.

The final product is an integrated system which combines the individual programs developed for each of the three devices onto a single data logging system. The development of this system streamlines the collection, processing, and storage of data from each sensor. This enhanced functionality enables the lab to broadcast continuous real-time data from each sensor through a common interface. This, in turn, allows data to be sent to the open access data viewing website, where real-time LEWAS watershed data is accessed by researchers, educators and students.

\subsection{Quality Assurance}

Data quality is a priority and appropriate steps are taken to ensure that data disseminated by the LEWAS lab are consistently accurate. In addition to data transmitted directly from the environmental sensors at the site, other supporting watershed data is collected and processed for quality assurance. This data includes the storm water network infrastructure, land use, precipitation, cross-section profiles, velocity profiles, and visual data captured by the network camera. Measures are also taken to ensure that data received from the environmental sensors is accurate. These measures include routine calibration, maintenance, and environmental measurements with additional equipment to provide supporting data.

\section{Case Studies}

Continuous data collection using environmental sensors has been promoted as a way of better understanding catchment processes (Kirchner et al., 2004). The LEWAS lab team seeks to better understand these processes through continuous monitoring at frequent sampling intervals (1-3 minutes) to fully capture the hydrologic responses of the watershed. The shortest intervals possible for each sensor were chosen in order to capture the maximum possible extent of the hydrologic and hydrochemical processes. The water quality Sonde collects data at three minute intervals while the Argonaut-SWADCP collects data at one minute intervals. Water quantity and quality changes in this small, urban watershed can happen in a matter of minutes and the high resolution of data collection at the LEWAS site enables the capture of acute events as they happen. The critical importance of high resolution temporal data is illustrated in two case studies, a two day series of summer storms with resultant fast runoff responses and a second case study focused on chloride concentration due to runoff from deicing operations.

The first case study illustrates the need for highfrequency data through the change in water temperature and flow during storm events that occurred on July 23 - 24, 2012 (Figure 4). During the July 23,2012 storm, the water temperature increased by $4.7^{\circ} \mathrm{C}$ within 3 minutes. During the following July 24, 2012 storm, the rising limb of the hydrograph increased from $0.023 \mathrm{~m} 3 / \mathrm{sat}$ base flow to a peak of $2.11 \mathrm{~m} 3 / \mathrm{s}$ within 12 minutes. If the Argonaut-SW ADCP had been sampling at larger 15 minute intervals, the peak of this storm may have been completely missed and could have been underestimated by as much as $26 \%$.

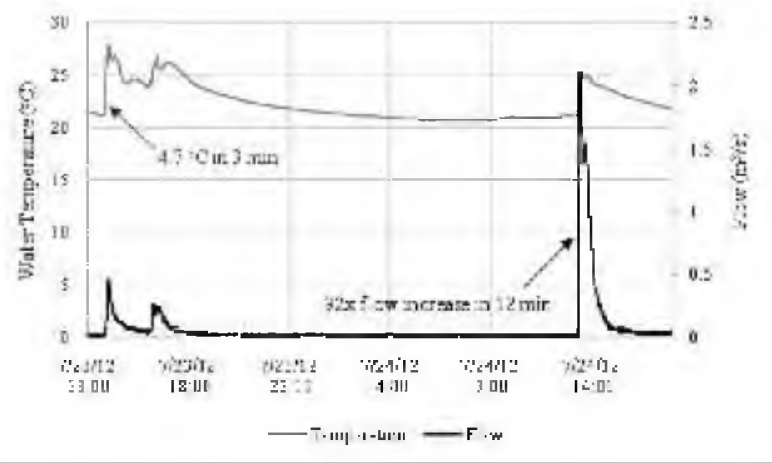

Figure 4. July 23 - 24, 2012 Storm Events.

In the second case study, the LEWAS data captured acute trends in specific conductance due to deicing runoff during a series of flash storm events on March 24 - 25, 2013.In anticipation of a winter storm event, maintenance crews applied salts and a deicing solution on roads and sidewalks within the watershed. The snow and abrupt warming runoff events caused the salt and deicing solution to runoff the roads, into the storm water network and into Webb Branch, where the LEWAS sensors recorded the data. Detecting these trends is essential for understanding what effects these events might have on aquatic health. During this event, shown in Figure 5, specific conduct ancereached $7310 \mu \mathrm{S} / \mathrm{cm}$, well beyond typical brackish or saline water $(4300 \mu \mathrm{S} / \mathrm{cm})$, and well above the chronic toxicity threshold for in-stream conductance impairment to freshwater fish 
communities (3000-3500 $\mu \mathrm{S} / \mathrm{cm})$ above the chronic toxicity threshold for in-stream conductance impairment to freshwater fish communities $(3000$ $3500 \mu \mathrm{S} / \mathrm{cm}$ ). (Kimmel \& Argent, 2009).

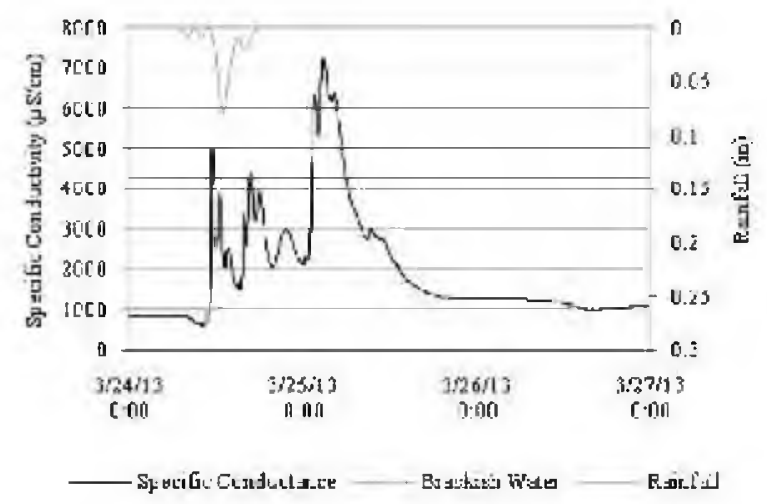

Figure 5.Specific conductivity response to winter precipitation

To further understand how this might affect the aquatic life in the stream, the spike in specific conductance in the stream is related to chloride concentrations. Specific conductance represents the ability of water to conduct electrical current and can be used to approximate the Total Dissolved Solids (TDS) in the water (Howard, 1933).Many road deicing salts and solutions contain high levels of chloride, which when flushed into receiving water bodies can cause acute chloride toxicity (Corsi et al., 2010). Acute chloride toxicity refers to the potential exceedance of species' tolerance caused by a one time, sudden, high exposure to chloride. Various aquatic species are sensitive to acute toxicity levels of contaminants found in urban storm water runoff. The United States Environmental Protection Agency (EPA)sets recommended water quality criteria for acute impairment limits in freshwater bodies across the United States, including maximum acute chloride concentrations.

A study compared 24 stream locations that recorded specific conductance and chloride concentrations in the Broad Run watershed in Fairfax County, Virginia in order to develop a general relationship when the specific conductance is over $1,000 \mu \mathrm{S} / \mathrm{cm}$, indicating heavy road salt content (Sanford et al., 2011). Thisrelationship, $\mathrm{Cl}=$ (0.33) SCwhere $\mathrm{Cl}$ is chloride concentration in $\mathrm{mg} /$, and $\mathrm{SC}$ is the specific conductance in $\mu \mathrm{S} / \mathrm{cm}$, was applied to the specific conductance data collected at the LEWAS site. There are limitations to using this regression equation since the relationship is not specific to the LEWAS site. However, given that this equation was developed in similar urban watersheds at various locations under comparable conditions, it provides a general relationship and an indication of the possible chloride exceedances during this event.

Using this specific conductance to chloride concentration relationshipreveals that chloride levels are estimated to reach up to $2,193 \mathrm{mg} / \mathrm{l}, 155 \%$ more than the EPA recommended level of $860 \mathrm{mg} / 1$ for acute toxicity. Figure 6illustrates the trend in estimated chloride concentrationat three minute intervals over the period of the storm against the EPA recommended limit. The chloride concentration during these storm events exceeds the EPA recommended limit for a combined period of 13.25 hours during a total span of 23 hours (Figure 6).In order to show the difference in sampling interval results, this figure illustrates estimated chloride concentrations atboth 3 minutes and 1 hour sampling intervals. In these polluto graph, the exceedance of the first peak beyond the EPA recommended limit is completely missed at a 1 hour sampling interval.

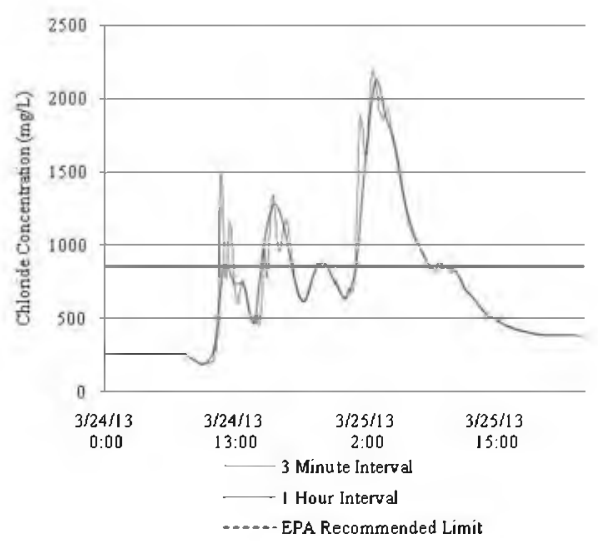

Figure 6. Estimated chloride concentration in the LEWAS stream

Although the capture of chloride concentrations from deicing runoff by using specific conductance as a surrogate is not new, the characterization of the concentration trends in this study suggests that continuous monitoring of deicing runoff is necessary to properly capture the behavior of acute exceedances within the system. This example highlights the potential of continuous environmental monitoring at frequent sampling intervals in assessing the impacts that human behaviors can have on the aquatic environment in a small urbanized watershed. Examples such as this also have applications for hands-on learning in courses such as hydrology as discussed in the following section. 


\section{Classroom Integration}

A key goal of the NSF-sponsored project supporting this work is to integrate these innovative case studies and continuous environmental data from the LEWAS into the undergraduate curriculum for enhancing teaching and learning practices. This is done through LEWAS-based active learning modules that seek to increase student learning and motivation through student-centered activities and exercises. The lab has been integrated into courses at Virginia Tech across multiple departments including Engineering Education, Civil and Environmental Engineering, Crop and Soil Environmental Sciences and Geosciences, reaching over 5,000 students since 2009 (Lohani et al.,2009; Delgoshaei et al.,2010; Delgoshaei, 2012; Dymond et al., 2013; Delgoshaei and Lohani, 2014; McDonald et al., 2014).Results from priorstudies have shown that having access to real-time environmental data through the LEWAS lab has increased student motivation in multiple courses. For example, in a study with 150 engineering freshmen at Virginia Tech in spring 2012, it was shown that having access to real-time water and weather data through the LEWAS improved students' motivation to learn about water sustainability issues .

\subsection{Classroom Integration and Assessment Methods}

As part of an ongoing NSF project, the LEWAS has been integrated into asenior level Hydrology course (27 students) at Virginia Tech in the spring 2012 semester. The goal of the project is to enhance student learning in the classroom by incorporating LEWASbased, hands-on student activities that engage the students in active and cooperative learning while supporting classroom goals. Active learning is a theory that proposes that students learn most effectively when they are engaged in the learning process by doing meaningful activities that require them to think about what they are doing. Active learning both introduces student activity into the traditional lecture method and promotes student engagement (Faust and Paulson, 1998). Studies have shown that students who are interactively engaged through active, student-centered classroom activities learn and retain more information (Prince, 2004). In addition, there is evidence that student learning improves through cooperative learning methods where students work in groups to achieve a common goal (Johnson et al., 2010). Each activity seeks to promote active and cooperative learning through student-centered modules that give students hands-on experience in data collection, processing, and watershed computations.

An advantage of the LEWAS is the ability to collect, store, and transmit data in real-time, which can be displayed through an environmental virtual or remote lab, such as the live data viewer. Here students can explore the environment, examine case studies, and view live data. Virtual labs are software that simulate the real environment, whereas remote labs are labs where experiments are conducted remotely across the Internet. Virtual labs have been shown to be effective in improving student understanding of important engineering concepts (Baher, 1998; Koretsky et al., 2011, Kollöffel and de Jong, 2013). Applications of remote labs in engineering education have also been shown to improve student understanding of engineering concepts (Gurocak, 2001; Alexander and Smelser, 2003) and are comparable to hands-on labs (Ogot et al., 2003; Corter et al., 2011).

The development of the LEWAS learning modules were guided by the Blooms Revised Cognitive Taxonomy (Anderson et al., 2001). Student learning outcomes in a hydrology course can be aligned with levels 1-5 of Blooms taxonomy. Example in this context are (1) remembering concepts like what is a watershed, and where does its water go, (2) understanding topics such as water quantity and quality parameters, data sensors, and human development impacts on a watershed, (3) applying what they know such as water flow represented as a hydrograph and precipitation represented as a hyetograph, (4) analyzing data such as in computing runoff to rainfall ratios, and (5) evaluating problems such as the impacts from land cover changes and different watershed events.

The experimental design for the hydrology course followed a one-group pretest/posttest design (Singleton and Straits, 2010). Students were given an assessment questionnaire early in the semester following an introduction to the LEWAS and another questionnaire following completion of the LEWASbased hydrology modules. Assessment questions were opened ended and did not contain any quantitative questions; however, assessment results were analyzed for common themes among the student responses and coded responses were quantized (Moskal, 2008). Codes and themes of the student responses were developed by (1) familiarizing the researcher to the data through reading and re-reading the data, (2) generating initial codes, and (3) gathering 
the codes with the help of Nvivo software to identify potential themes (Robson, 2002). Multiple team members coded the data and discussed their results among each other to ensure credibility of the coding process and any differences in the codes and themes were discussed and reconciled through an iterative process (Leydens, 2004).

The experimental design lends itself to multiple internal validity threats including history (i.e., an event could occur during treatment that influences the outcomes), maturation (i.e., participants could mature or change throughout the treatment thereby influencing the results), selection (i.e., students in the class will not be randomly selected but are chosen due to accessibility and resource constraints), testing (i.e., the pretest could cause the participants to become familiar with the material), or interaction effects through a combination of threats (Singleton and Straits, 2010). The sample of students is also nonrandom as it only contains students within one course, thus the generalizability of the results will be limited because the sample is not statistically representative of the greater population of engineering students.

\subsection{LEWAS-Based Classroom Modules}

In the senior level hydrology course at VT, students used data collected at the LEWAS site to understand various hydrologic concepts including runoff coefficients in urbanized watersheds, the relationship between land cover and water quality, and the importance of environmental monitoring. Classroom modules included both in-person visits to the LEWAS site for field observations and in-class studentcentered exercises and homework assignments that utilizedhigh frequency data sets. An example is the Storm Characteristics Module that used flow and weather data generated by the LEWAS to illustrate the rainfall-runoff relationship in a small urbanized watershed. Given precipitation and flow data, students were able to precisely estimate the volume of storm flow from the hydrograph and volume of precipitation that fell over the LEWAS watershed for a given rainfall-runoff event. Students worked in pairs to compute runoff to rainfall ratios and comment on how their results could be used to indicate the amount of rainfall that infiltrated the ground, evaporated, or became intercepted by vegetation. High-frequency data allowed students to compute the storm flow and see the flashiness of a small urbanized watershed through the characterization of the hydrograph. Students also completed the same assignment using
USGS flow data (collected at 15 minute intervals) for larger, less developed watersheds. This provided students with an understanding of the differences in hydrographs from large undeveloped watersheds and small urban watersheds that reflect their size and land cover.

A second example is the Watershed Wiki Module which promoted active and cooperative learning through a hands-on group assignment that gave students the opportunity to investigate physical changes in the watershed and draw their own assessments. Students were assigned to teams (3-4 students) that took turns throughout the semester visiting the LEWAS field site and writing daily reports on the class blog about the conditions at the site, performance of the equipment, and the data monitoring results. The groups took on the responsibility as a watershed assessment team for an assigned week and prepared data tables and graphs of weather, flow, and water quality data, describing trends and particular events that occurred over the week using LEWAS data as well as their own observations (VT Fall 2012 Hydrology Blog. Accessed September 2012 - March 2015https://blogs.lt.vt.edu/cee4304f2012/).

\subsection{Student Assessment Results}

Students were asked similar questions in the preand post-test assessments to determine how their experience with the LEWAS affected their perceived learning gains. Student responses indicated that the perceived role of the LEWAS in helping them learn hydrologic concepts did not change over the course of the semester. When asked "How can this system help you learn hydrologic concepts?", the majority of student found that experience with practical realworld data helped them the most (65\% pre-test; $62 \%$ post-test). For example, in the post-test one student stated "Comparing direct physical observations with detailed data was helpful in matching real-world situations to calculations", and another commented "We were able to see how the concepts learned in class apply to an actual stream." These students found that the ability to connect what they were doing in class with an actual stream nearby helped them to understand hydrologic concepts.

A noticeable difference in the pre-and post-tests were the student responses to how the system would help them learn about sustainable development. When asked "How did this system help educate you about

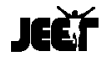


sustainable development?", the majority of students felt initially that the system would help show them how land use affects runoff (37\%). While the same percentage indicated so in the post-test $(36 \%)$, the majority of students $(48 \%)$ in the post-test believed that it was the ability of the LEWAS data to show what actually occurs in a stream that helped to educate them the most about sustainable development. This would suggest that an urban watershed monitoring system that communicates what is occurring in a stream through continuous data is valuable in educating students about the impacts of development.

Additional questions were asked in the post-test to further examine student experiences with the LEWAS. Students were asked in what ways they would incorporate a similar system into a future course. This required students to think about how they would teach someone else hydrology concepts using the LEWAS system. Overall students were able to synthesize their experiences with the LEWAS and recommend new ways in which it could be incorporated into hydrology education. One student stated "I would make a few more assignments related to various concepts discussed in the latter part of the class (i.e. convolution, deconvolution, channel routing, etc.)." This student and others found value in hands-on active learning activities that connected what they were doing in the classroom with reality and were able to articulate new ways in which the LEWAS could be applied within a hydrology education context.

To determine what perceived value students found in the system, the post-test assessment questionnaire asked students what value they found in monitoring of water quantity and water quality. The results indicate that a majority of the students (84\%) found access to continuous real-time monitoring to be valuable for understanding real-world applications and data collection. The remaining students cited the usefulness of high-frequency data in developing hydrologic and water quality models. In reference to systems such as the LEWAS, one student stated, "I believe there is a great value in monitoring water quantity and quality. For students it gives us the chance to understand hydrology outside of the classroom. It also creates real data to prove the effects of development on the stream." The use of highfrequency data and case studies in the classroom helped this student and others understand what effects human development has on the stream. The hands-on active and cooperative learning experience also gave them the chance to go out of the classroom and work with real, locally captured data, which allowed them to make connections between the data they received from the LEWAS and what they could observe around them. This finding supports previous research that suggests that students learn more when they are able to connect what they are doing in the classroom to the physical environment (Cantor, 1997).

While there are multiple limitations to the study, including internal validity threats discussed in Section 5.1 , the results from the assessment suggest that the system positively impacted student perceived learning. The biggest value was in connecting what students do in class to reality, as the majority of students indicated that they would continue to use the system in future courses for hands-on data collection and most students found the system to be valuable for understanding real-world applications and data collection. Information from the assessment results is being used to improve classroom modules for future courses, including the spring 2015 hydrology course at VT. The goal for this course and others is to continue to investigate how continuous real-time data enables students to gain a better understanding of hydrologic responses through student-centered classroom modules.

The implementation of LEWAS modules into a hydrology course illustrates some of the many advantages to using a system like the LEWAS in classroom instruction versus readily available watershed data such as that is provided by the USGS. As the case studies demonstrate, higher resolution data gives a better picture of what is actually happening in small urbanized watersheds. The majority of readily available hydrologic data are mostly applicable for large rural or mixed land use watersheds, whereas a system like LEWAS can give high resolution data for small watersheds that have faster response times and different characteristics than watersheds typically monitored by federal or state agencies with publically accessible data. Another educational advantage of a system such as this is the ability to have a system at any location, such as a local stream, that the students can visit in-person. This allows students to see the sensors and understand how they function in collecting data, as opposed to only receiving flow values from a website. A webcam at the site also allows students to match the data with visual images in order to relate parameters such as flow rate, turbidity, rainfall rate, etc. with what they can see from a picture. Finally, summer thunderstorms may 
dramatically varyspatially, and a system such as LEWAS provides students with flow, water quality, and precipitation data from a single location, as opposed to other data sources that may be sparse and disconnected. Disadvantages of a system like the LEWAS include the cost of equipment purchase, time and expertise for sensor installation, programming, systems integration and ongoing efforts to maintain and calibrate the sensors.

\section{Conclusions}

This paper demonstrates how a continuous realtime watershed monitoring system can be developed and implemented for watershed education research. Results from the case studies suggest that highfrequency watershed monitoring is helpful incapturing acute watershed events in a small urbanized watershed that would not be fully characterized with longer sampling intervals.In addition, assessment results from student-centered active learning modules have shown positive learning gains in students that have access to continuous realtime data.

The favorable results in demonstrating and teaching watershed concepts and principles to undergraduate hydrology students has led to the development of LEWAS based modules for future courses. Future plans include continued integration of the lab into the Hydrology course at VT as well as freshman level courses at VWCC. In addition, faculty members from other departments at VT (e.g., geosciences, biological sciences, and environmental sciences), other local universities and colleges (East Carolina University, and John Tyler Community College) and international universities in Australia and India have expressed interest in integrating the LEWAS into their curricula.

Ongoing development of the system will eventually result in data dissemination beyond the live data-viewer to the Online Watershed Learning System (OWLS), which is being created as an interactive watershed education tool as part of an ongoing $\mathrm{PhD}$ dissertation in Engineering Education. Current and future work will seek to build upon the research presented here by using the OWLS to improve learning and motivation in community college, undergraduate and graduate students. Case studies and details of the OWLS, currently being implemented into spring 2015 courses, will be disseminated in the near future. A description of the development of the initial version of the OWLS can be found in Brogan et al. (2014).

The use of continuous watershed monitoring labs for both research and education has enormous potential. Systems such as the LEWAS can provide insights into watershed behaviors and improvements to student learning through access to real-time environmental data. The LEWAS demonstrates how the integration of different commercial sensors through custom data collection hardware and software programming can produce reliable and continuous data. The LEWAS is a viable alternative to the high-cost of data collection hardware and software when using different commercial sensors. Challenges in creating such a lab include cost of equipment, expertise, and ongoing maintenance. However, as the need for new ways to develop student-centered learning environments and to understand hydrologic processes continues, systems such as the LEWAS will play an important role in improving watershed education and our understanding of hydrologic systems.

\section{Acknowledgement}

The authors acknowledge LEWAS labs current (Debarati Basu, Darren Maczka, Todd Aronhaldt, Josh Gozum, Marcus Wanner, and Thomas Westfall) and former (Parhum Delgoshaei, Hari Raamanathan, Aaron Bradner, Chelsea Green, and Mark Rogers) students who are not included in authorship. Support provided by Virginia Tech's Department of Engineering Education, College of Engineering, and Institute for Critical Technology and Applied Science (ICTAS) is sincerely acknowledged. The authors also acknowledge the support of the National Science Foundation through various programs (Grant \#s: DLR: 0431779, TUES: 1140467, and REU Site awards-1062860/1359051). Any opinions, findings, and conclusions or recommendations expressed in this article are those of the author(s) and do not necessarily reflect the views of the U.S. National Science Foundation. $z$

\section{References}

Alexander, D. G., \& Smelser, R. E. (2003), Delivering an engineering laboratory course using the Internet, the post office, and a campus visit. Journal of Engineering Education, 92(1), 79-84.

Anderson, L. W., Krathwohl, D. R., Airasian, P. W., Cruikshank, K. A., Mayer, R. E., Pintrich, P. R., Raths, J., \& Wittrock, M. C. (eds.)(2001),A taxonomy for 
learning and teaching and assessing: A revision of Bloom's taxonomy of educational objectives. Addison Wesley Longman.

Arnscheidt, J., McGrogan, H., \& McCormick, S.(2005), High-resolution phosphorus transfers at the catchment scale: the hidden importance of non-storm transfers. Hydrology and Earth System Sciences (HESS) 9(6): 685-691.DOI:10.5194/hess-9-6852005

Aubert, A. Kirchner, J., Gascuel-Odoux, C., Faucheux, M., Gruau, G.,\& Mérot, P.(2014),Fractal Water Quality Fluctuations Spanning the Periodic Table in an Intensively Farmed Watershed. Environmental Science \& Technology 48(2): 930937. DOI: $10.1021 /$ es403723r

Cantor, J.A.(1997), Experiential Learning in Higher Education: Linking Classroom and Community. ERIC Clearinghouse on Higher Education, Washington, D.C.

Baher, J.(1998), How articulate virtual labs can help in thermodynamics education: a multiple case study, Frontiers in Education Conference, 1998. FIE ' 98. 28th Annual, 2, 663-668 vol.2, Nov. 4-7, 1998, doi: 10.1109/FIE.1998.738764

Brogan, D.S., Lohani, V.K., \& Dymond, R.L. (2014),Work in progress: The Platform-Independent Remote Monitoring System (PIRMS) for situating users in the field virtually,Proc. 2014 ASEE Annual Conference \& Exposition, Indianapolis, IN, 2014.

Corsi, S.R., Graczyk, D.J., Geis, S.W., Booth, N.L., \& Richards, K.D.(2010), A Fresh Look at Road Salt: Aquatic Toxicity and Water-Quality Impacts on Local, Regional, and National Scales. Environmental Science \& Technology, 44(19), 7376-82. doi:10.1021/es101333u.

Corter, J. E., Esche, S. K., Chassapis, C., Ma, J., \& Nickerson, J. V. (2011), Process and learning outcomes from remotely-operated, simulated, and hands-on student laboratories. Computers \& Education, 57(3), 2054-2067.

Delgoshaei, P., Lohani, V.K. \& Green, C.(2010), Introducing Dataflow Programming in a Freshman Engineering Course with Applications in Sustainability Education.Proc. 2010 ASEE Annual Conference \& Exposition. Louisville, Kentucky.

Delgoshaei, P. (2012), Design and Implementation of a Real-Time Environmental Monitoring Lab with Applications in Sustainability Education (Doctoral Dissertation).Virginia Polytechnic Institute and State University, Blacksburg, Virginia.
Delgoshaei, P., \& Lohani, V. K.(2014),Design and Application of a Real-Time Water Quality Monitoring Lab in Sustainability Education, International Journal of Engineering Education, 30(2): 1-14.

Dymond, R.L., Lohani, V.K., Brogan, D., \& Martinez, M.(2013), Integration of a Real-Time Water and Weather Monitoring System into a Hydrology Course.Proc.120th ASEE Annual Conference \& Exposition. Atlanta, Georgia.

Faust, J. L., \& Paulson, D.R., 1998. Active learning in the college classroom, Journal on Excellence in College Teaching, 9(2), pp. 3-24.

Glasgow, H.B., Burkholder, J., Reed, R., Lewitus, A., \& Kleinman, J.(2004), Real-time remote monitoring of water quality: a review of current applications, and advancements in sensor, telemetry, and computing technologies. Journal of Experimental Marine Biology and Ecology, 300(1-2): 409-448. DOI: 10.1016/j.jembe.2004.02.022

Gurocak, H. (2001), e-Lab: An Electronic Classroom for Real Time Distance Delivery of a Laboratory Course. Journal of Engineering Education, 90(4), 695-705.

Hotaling, L., Lowes, S., Stolkin, R., Lin, P., Bonner, J., Kirkey, W., \& Ojo, T.(2012), SENSE IT : Teaching STEM principles to middle and high school students through the design, construction and deployment of water quality sensors. Advances in Engineering Education, 3(2): 1-34.

Howard, C.S.(1933), Determination of Total Dissolved Solids in Water Analysis. Industrial \& Engineering Chemistry Analytical Edition5(1), 46.DOI: 10.1021/ac50081a004

Iqbal, M. (2013), Field and Lab-based Activities for Undergraduate Students to Study the Hydrologic Environment. Proc. 2013 TUES PIs Conference. Washington, DC, p. A135.

Johnson, D.W., Johnson, R.R., \& Smith, K.A. (2010),Cooperative Learning Returns to College What Evidence is There That it Works?.Change: The Magazine of Higher Learning, 30(4): 2635.DOI:10.1080/00091389809602629

Jones, A. S., Stevens, D. K., Horsburgh, J. S.,\& Mesner, N. O. (2011), Surrogate Measures for Providing High Frequency Estimates of Total Suspended Solids and Total Phosphorus Concentrations. Journal of the American Water Resources Association (JAWRA), 47: 239-253. DOI: 10.1111/j.1752-1688.2010.00505.x

Kavetski, D., Fenicia, F., \& Clark,M. P.(2011), Impact 
of temporal data resolution on parameter inference and model identification in conceptual hydrological modeling: Insights from an experimental catchment.Water Resources Research, 47(5). DOI:10.1029/2010WR009525.

Kimmel, W. G., \& Argent, D.G.(2009), Stream Fish Community Responses to a Gradient of Specific Conductance. Water, Air, and Soil Pollution, 206(14): 49-56. DOI: $10.1007 / \mathrm{s} 11270-009-0085-\mathrm{x}$

Kollöffel, B., \& de Jong, T.(2013), Conceptual Understanding of Electrical Circuits in Secondary Vocational Engineering Education: Combining Traditional Instruction with Inquiry Learning in a Virtual Lab. Journal of Engineering Education, 102: 375-393. doi: 10.1002/jee.20022

Koretsky, M., Kelly, C., \& Gummer, E.(2011), Student Perceptions of Learning in the Laboratory: Comparison of Industrially Situated Virtual Laboratories to Capstone Physical Laboratories. Journal of Engineering Education, 100: 540-573. doi: 10.1002/j.2168-9830.2011.tb00026.x

Kirchner, J.W., Feng, X., Neal, C., \& Robson, A.(2004), The fine structure of water-quality dynamics: the (high-frequency) wave of the future.Hydrological Processes, 18(7): 1353-1359. DOI: 10.1002/hyp.5537

Leydens, J. A., Moskal, B. M., \& Pavelich, M. J. (2004), Qualitative methods used in the assessment of engineering education. Journal of Engineering Education, 93(1), 65-72.

Lohani, V.K., Delgoshaei, P., \& Green, C.(2009), Integrating LabVIEW and Real-Time Monitoring into Engineering Instruction. Proc. 2009 ASEE Annual Conference\& Exposition. Austin, Texas.

McDonald, W.M., Dymond, R.L., Lohani, V.K., Brogan, D.S., \& Clark, R.L.(2014), Integrating a Real-Time Remote Watershed Monitoring Lab into Water Sustainability Education. Proc. 2014 ASEE Annual Conference\& Exposition. Indianapolis, Indiana.

Moraetis, D., Efstathiou, D., Stamati, F., Tzoraki, O., Nikolaidis, N., Schnoor, J., \& Vozinakis, K.(2010), High-frequency monitoring for the identification of hydrological and bio-geochemical processes in a Mediterranean river basin. Journal of Hydrology, 389(1-2):127-136.DOI:10.1016/j.jhydrol.2010.05 .037

Moskal, B.(2008), Using Assessment Results for
Improving Student Learning. In:Designing Better Engineering Education Through Assessment, Joni Spurlin, Sarah Rajala, and Jerome Lavelle (Editors), Stylus Publishing, Virginia, pp. 117-148.

Ogot, M., Elliott, G., \& Glumac, N. (2003), An Assessment of In Person and Remotely Operated Laboratories. Journal of Engineering Education, 92(1), 57-64.

Prince, M.(2004), Does Active Learning Work? A Review of the Research. Journal of Engineering Education (JEE), 93(3): 223-231.DOI: 10.1002/j.2168-9830.2004.tb00809.x

Robson, C. (2002), Real world research. Oxford: Blackwell.

Sanford, W., Nelms, D., Pope, J., \&Selnick, J.(2011), Quantifying Components of the Hydrologic Cycle in Virginia using Chemical Hydrograph Separation and Multiple Regression Analysis Scientific Investigations U.S. Geological Survey Scientific Investigations Report 2011 - 5198, 152 p.http://pubs.usgs.gov/sir/2011/5198.

Singleton, R.A., \& Straits, B.C. (2010), Approaches to social research. Oxford University Press: New York, NY

Thompson, S.E., Ngambeki, I.,Troch, P.A., Sivapalan, M., \& Evangelou, D.(2012), Incorporating Student-Centered Approaches into Catchment Hydrology Teaching: A Review and Synthesis. Hydrology and Earth System Sciences, 16: 32633278. DOI:10.5194/hess-16-3263-2012

Upton, E., \& Halfacree, G. (2014), Raspberry Pi user guide. John Wiley \& Sons.

U.S. Environmental Protection Agency (USEPA)(1986), Quality Criteria for Water. Office of Water Regulations and Standards, Washington, DC.

U.S. Environmental Protection Agency (USEPA) (2002),Methods for Measuring the Acute Toxicity of Effluents and Receiving Waters to Freshwater and Marine Organisms, Fifth Edition. Office of Water, Washington, DC.

Virginia Department of Environmental Quality (VDEQ) (2006),Upper Stroubles Creek Watershed TMDL Implementation Plan Montgomery County, Virginia.VT-BSE Document No. 2005-0013, Blacksburg, Virginia.

Virginia Department of Environmental Quality (VDEQ)(2012),305(b)/303(d) Water Quality Assessment Integrated Report. Richmond, VA. 